\title{
Immunohistochemical Localization of Annexin A5 in the Mammary Gland of Rats: Up-Regulation of Expression by Pup Removal
}

\author{
Duangjai RIEANRAKWONG ${ }^{1)}$, Tomohiro YONEZAWA ${ }^{1)}$, Shiro KURUSU ${ }^{1)}$ and Mitsumori KAWAMINAMI)* \\ ${ }^{1)}$ Laboratory of Veterinary Physiology, School of Veterinary Medicine, Kitasato University, Towada, Aomori 034-8628, Japan
}

(Received 1 August 2009/Accepted 19 August 2009/Published online in J-STAGE 5 November 2009)

\begin{abstract}
The distribution of annexin A5, a cytosolic protein related to gonadotropin releasing hormone action, was examined in the mammary gland of rats by immunohistochemistry with special reference to changes by lactation. Annexin A5 was observed in the interstitial tissues but not alveolar cells in virgin rats, while mammary epithelial cells became positive for annexin A5 in pregnant rats. The intensity of annexin A5 was decreased in lactating rats and dramatically increased after weaning, especially on the nucleus. When pups were removed from their dam at mid-lactation (day 10), annexin A5 was also increased on day 12. Apoptotic epithelial cells detected by terminal deoxynucleotidyl transferase nick end labeling were simultaneously increased. Annexin A5 mRNA expression of mammary tissues was increased after pup removal. These results are the first to demonstrate the distribution of annexin A5 in the mammary glands of lactating rats, and the enhanced expression in mammary epithelial cells after lactation suggests its involvement in mammary epithelial cell involution.
\end{abstract}

KEY WORDS: annexin A5, mammary gland, mammary involution.

Annexin A5 is a member of the annexin family of proteins, which consists of 12 members in mammals [7]. Common features of annexin are their structural similarity and binding capacity to phospholipids $[5,8,16]$. Although the well conserved structure and diversity of family members suggests the biological significance of annexins, the physiological functions of all annexins are still obscure. Among annexins, annexin A1 has been shown to mediate glucocorticoid function in two instances, anti-inflammation and negative feedback on corticotropin secretion $[3,6]$. On the other hand, annexin A7 has been demonstrated to fuse membranes and proposed to function at exocytosis [4]. Annexin A5 is used in a commercial kit to detect early apoptotic cells by its high affinity to phosphatidylserine. This feature may be related to its anti-coagulating activity [22].

We previously found that annexin A5 is specifically expressed in pituitary gonadotropes and that its expression is stimulated by gonadotropin releasing hormone (GnRH) [11]. We subsequently demonstrated that the expression of annexin A5 is also enhanced by GnRH in the corpus luteum and Leydig cells [13, 24]. We have also demonstrated that annexin A5 is involved in GnRH stimulation of gonadotropin release [11]. Although the exact function of annexin A5 is not known yet, annexin A5 could be utilized as a biomarker of GnRH action in cells expressing GnRH receptor.

While GnRH is well known as a hypothalamic neuropeptide hormone stimulating gonadotropin secretion in pituitary gonadotropes, GnRH and its receptor have been demonstrated in various peripheral tissues [19]. Among these, variation in the expression of $\mathrm{GnRH}$ in mammary tissues

\footnotetext{
* Correspondence to: Kawaminami, M., Laboratory of Veterinary Physiology, School of Veterinary Medicine, Kitasato University, Towada, Aomori 034-8628, Japan. e-mail:mitsumor@vmas.kitasato-u.ac.jp
}

has been reported $[9,18]$. In the present study, we examined the variation of annexin A5 expression in mammary tissues. We found that the expression of annexin A5 changes along with the physiological status of the mammary gland, and a significant increase after lactation was observed. The latter finding suggests a role for annexin A5 in the involution of mammary tissues after lactation.

\section{MATERIALS AND METHODS}

Experimental animals: Adult female Wistar Imamichi rats bred in our laboratory were maintained at $23 \pm 3^{\circ} \mathrm{C}$ with a controlled light cycle of 14L:10D (light on 5:00-19:00 hr). Food and tap water were supplied ad libitum. Vaginal smears were taken daily, and only rats showing regular 4day estrous cycles were mated. The presence of sperm in vaginal smears was confirmed on the morning of estrus. The day of delivery was designated as day 0 of lactation. The number of pups was adjusted to eight on day 1 of lactation. All experiments were performed according to the guidelines for animal experiments of Kitasato University, and the experimental plan was approved by the Committee for Laboratory Animals, Care and Use at School of Veterinary Medicine, Kitasato University.

Tissue preparation for histological analysis: Rats deeply anesthetized with Somnopentil (Kyoritsu Seiyaku Co., Tokyo, Japan) were infused with $50 \mathrm{~m} l$ of phosphate buffered saline (PBS; 0.1 M, pH 7.4) via the left ventricle and then with $50 \mathrm{ml}$ of $4 \%$ paraformaldehyde (PFA). The right atrial auricle was cut off. The inguinal mammary glands were collected and further fixed in 4\% PFA overnight at $4^{\circ} \mathrm{C}$. Tissue blocks were washed, dehydrated and embedded in paraffin. Four-micron tissue sections were made, dried in an incubator at $37^{\circ} \mathrm{C}$ overnight and subjected to immunohis- 
tochemistry or Terminal deoxynucleotidyl transferase nick end labeling (TUNEL) analysis.

Immunohistochemistry: After hydration, the sections were incubated with $2.5 \%$ normal horse serum for $30 \mathrm{~min}$ to reduce non-specific antibody binding. The first antibody was anti annexin A5 rabbit serum raised in our laboratory [21]. The antiserum was diluted to $1: 10,000$, and the sections were incubated with the serum overnight at $4{ }^{\circ} \mathrm{C}$. The second antibody system for visualization was the Immpress reagent anti-rabbit IgG POD kit (Vector Laboratories, Burlingame, CA, U.S.A.). The specimens were counterstained with hematoxylin.

TUNEL analysis: Apoptotic cells were detected by TUNEL reaction using In Situ Cell Death Detection Kit POD (Roche Diagnostics Gmbh, Tokyo, Japan) according to the manufacturer's protocol. The sections were counterstained with hematoxylin.

$R N A$ extraction and reverse transcription-real time polymerase chain reaction ( $P C R$ ): Inguinal mammary tissues were dissected, and total RNA was extracted with Trizol Reagent (Invitrogen, Tokyo, Japan). RNA samples were dissolved in diethylpyrocarbonate-treated water to $500 \mathrm{ng} /$ $\mathrm{m} l$ and subjected to reverse-transcription. RNA was reverse-transcribed to cDNA with a High Capacity cDNA Archive Kit (Applied Biosystems, Tokyo, Japan) according to the protocol supplied by the manufacturer. Then cDNA samples were subjected to real time PCR for measurement of the expression of annexin A5 mRNA. Universal PCR Master Mix (Applied Biosystems) was used for real time PCR. The PCR primers for measurement of annexin A5 mRNA were 5'-AAGTTCTTCGGAAGGCCATG-3' for the sense primer, 5'-CTCAGCAATCTGCTGGCG-3' for the anti-sense primer and CGACGAGGACAGCATCCTGAACCTGTT for the TaqMan probe. PCR was performed with 50 cycles of $94^{\circ} \mathrm{C}$ for $0.5 \mathrm{~min}, 65^{\circ} \mathrm{C}$ for $0.5 \mathrm{~min}$ and $72^{\circ} \mathrm{C}$ for $1.5 \mathrm{~min}$. A series of serially diluted cDNA from mammary tissue was used for drawing a standard curve. Each measured value was divided by that of the internal standard, ribosomal protein L19, and presented as expression level. The PCR primers for ribosomal protein L19 were 5'- CAGGAGATACCGGGAATCTAAG-3' for the sense primer, 5' - TGCCTTCAGTTTGTGGATGTG-3' for the anti-sense primer and TGACCGTCATATGTATCACAGCCTGTACCT for the TaqMan probe.

Statistics: Statistical analysis was performed using the Student's $t$ test.

\section{RESULTS}

The distribution of annexin A5 varied according to the physiological status examined. Fat cells and interstitial cells were positive for annexin A5 in the virgin rat. However, annexin A5 was not observed in the mammary epithelial cells, while the epithelial cells became positive in the pregnant rat (Fig. 1a). The area of the mammary alveoli was increased in the pregnant and lactating rats. The immunoreactivity of annexin A5 became weaker in the epithelial cells of lactating rats (day 10). The intensity of annexin A5 dramatically increased two days after the weaning on day 21 .

The expression of annexin A5 was also examined in forcibly weaned rats. Pups were removed on day 10 of lactation, and mammary tissues were collected two days after. Pup removal significantly increased annexin A5 in the mammary epithelial cells (Fig. 1b). The nuclear intensity of annexin A5 was increased. TUNEL positive epithelial cells were also increased in the epithelial cells.

The increase of annexin A5 was also seen in the expression of annexin A5 mRNA in the mammary tissues after pup removal (Fig. 1c).

\section{DISCUSSION}

The present results are first to demonstrate that annexin A5 is expressed in mammary epithelial cells. The expression rate varies along with the physiological status of the mammary gland. The expression of annexin A5 in mammary epithelial cells becomes obvious in pregnant rats. The mammary gland develops to synthesize milk during pregnancy via various hormones, especially prolactin [17]. So, the appearance of epithelial annexin A5 in the pregnant rat may be related to mammary development. The biggest change in the expression of annexin A5 was the dramatic increase after weaning. Mammary tissues involute very quickly after pup removal. The involution consists of two phases. In the first reversible phase, the apoptosis of epithelial cells occurs. If suckling stimulus is restarted, the gland becomes able to produce milk again. The second phase is irreversible, and tissue remodeling follows [1, 14, 20, 23]. As annexin A5 expression was increased within two days of pup removal, it seems to be involved in the first phase of involution. Annexin A5 was shown to locate on the nucleus in the involuting mammary epithelial cells. We have observed this kind of nuclear distribution for annexin A5 in the castration cells of the pituitary gland after ovariectomy [10]. These results suggest that annexin A5 has a nuclear function.

The annexin family of proteins consists of 12 members. Among them, annexin A5 is one of most studied annexins. However, its physiological relevance is not well understood. An annexin A5 knock-out mouse has been established, but no distinct phenotype has been reported $[2,15]$. We have revealed that annexin A5 is involved in GnRH stimulation of gonadotropin secretion [11]. In that study, anti-deoxynucleotide to annexin A5 mRNA was shown to inhibit the action of GnRH. On the other hand, recombinant annexin A5 stimulated LH and FSH release in primary culture of anterior pituitary cells. So, although further study is needed, annexin A5 may play a role in signal transduction in cells.

As GnRH has been demonstrated to stimulate the expression of annexin A5 in pituitary gonadotropes, luteal cells and Leydig cells [11-13, 24], annexin A5 seems to be a marker protein of GnRH action in the mammary gland. The present results show the specific distribution of annexin A5 in mammary epithelial cells, and suggest that GnRH would 

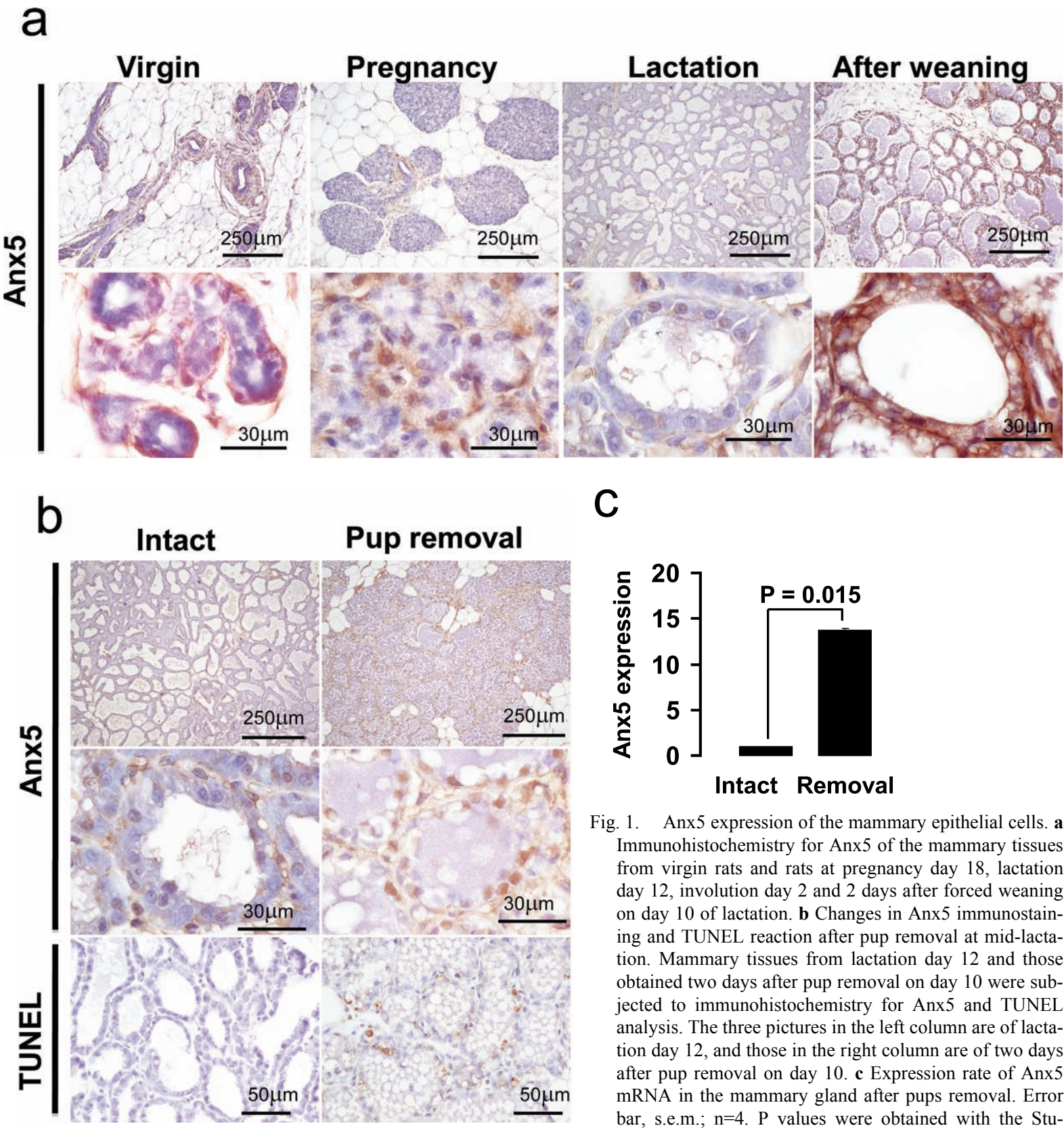

C

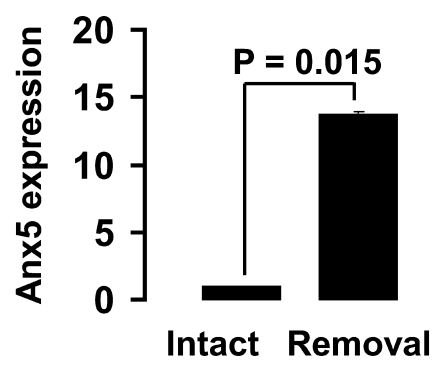

Fig. 1. Anx5 expression of the mammary epithelial cells. a Immunohistochemistry for Anx 5 of the mammary tissues from virgin rats and rats at pregnancy day 18 , lactation day 12, involution day 2 and 2 days after forced weaning on day 10 of lactation. b Changes in Anx 5 immunostaining and TUNEL reaction after pup removal at mid-lactation. Mammary tissues from lactation day 12 and those obtained two days after pup removal on day 10 were subjected to immunohistochemistry for Anx5 and TUNEL analysis. The three pictures in the left column are of lactation day 12 , and those in the right column are of two days after pup removal on day 10. c Expression rate of Anx5 mRNA in the mammary gland after pups removal. Error bar, s.e.m.; n=4. P values were obtained with the Student's t test.

act on the epithelial cells at involution. Interestingly, GnRH expression was detected in the pregnant and lactating rats, but not in the virgin rats $[9,18]$. Further study is needed to clarify the possibility of GnRH involvement in mammary involution, and in this regard is currently underway in this laboratory.

In summary, a putative signal protein of GnRH receptor, annexin A5, is extensively increased in the mammary epithelial cells after weaning. These data suggest that the GnRH-annexin A5 system would be involved in mammary involution.

\section{REFERENCES}

1. Baxter, F.O., Neoh, K. and Tevendale, M.C. 2007. The beginning of the end: death signaling in early involution. J. Mammary Gland Biol. Neoplasia 12: 3-13.

2. Brachvogel, B., Dikschas, J., Moch, H., Welzel, H., von der Mark, K., Hofmann, C. and Poschl, E. 2003. Annexin A5 is not essential for skeletal development. Mol. Cell Biol. 23: $2907-$ 2913.

3. Buckingham, J.C., Solito, E., John, C., Tierney, T., Taylor, A., Flower, R., Christian, H. and Morris, J. 2003. Annexin 1: a paracrine/juxtacrine mediator of glucocorticoid action in the 
neuroendocrine system. Cell Biochem. Funct. 21: 217-221.

4. Caohuy, H. and Pollard, H.B. 2002. Protein kinase C and guanosine triphosphate combine to potentiate calcium-dependent membrane fusion driven by annexin 7. J. Biol. Chem. 277: 25217-25225.

5. Crompton, M.R., Moss, S.E. and Crumpton, M.J. 1988. Diversity in the lipocortin/calpactin family. Cell 55: 1-3.

6. Flower, R.J. and Rothwell, N.J. 1994. Lipocortin-1: cellular mechanisms and clinical relevance. Trends Pharmacol. Sci. 15: 71-76.

7. Gerke, V. and Moss, S.E. 2002. Annexins: from structure to function. Physiol. Rev. 82: 331-371.

8. Gerke, V., Creutz, C.E. and Moss, S.E. 2005. Annexins: linking $\mathrm{Ca}^{2+}$ signalling to membrane dynamics. Nat. Rev. Mol. Cell Biol. 6: 449-461.

9. Ikeda, M., Taga, M., Sakakibara, H., Minaguch, H. and Vonderhaar, B.K. 1995. Detection of messenger RNA for gonadotropin-releasing hormone $(\mathrm{GnRH})$ but not for $\mathrm{GnRH}$ receptors in mouse mammary glands. Biochem. Biophys. Res. Commun. 207:800-806.

10. Kawaminami, M., Yamaguchi, K., Miyagawa, S., Numazawa, S., Ioka, H., Kurusu, S. and Hashimoto, I. 1998. Ovariectomy enhances the expression and nuclear translocation of annexin 5 in rat anterior pituitary gonadotrophs. Mol. Cell Endocrinol. 141:73-78.

11. Kawaminami, M., Etoh, S., Miyaoka, H., Sakai, M., Nishida, M., Kurusu, S. and Hashimoto, I. 2002. Annexin 5 messenger ribonucleic acid expression in pituitary gonadotropes is induced by gonadotropin-releasing hormone $(\mathrm{GnRH})$ and modulates GnRH stimulation of gonadotropin release. Neuroendocrinology 75: 2-11.

12. Kawaminami, M., Tsuchiyama, Y., Saito, S., Katayama, M., Kurusu, S. and Hashimoto, I. 2002. Gonadotropin-releasing hormone stimulates annexin 5 messenger ribonucleic acid expression in the anterior pituitary cells. Biochem. Biophys. Res. Commun. 291:915-920.

13. Kawaminami, M., Shibata, Y., Yaji, A., Kurusu, S. and Hashimoto, I. 2003. Prolactin inhibits annexin 5 expression and apoptosis in the corpus luteum of pseudopregnant rats: involvement of local gonadotropin-releasing hormone. Endo- crinology 144: 3625-3631.

14. Lund, L.R., Romer, J., Thomasset, N., Solberg, H., Pyke, C., Bissell, M.J., Dano, K. and Werb, Z. 1996. Two distinct phases of apoptosis in mammary gland involution: proteinase-independent and -dependent pathways. Development 122:181-193.

15. Mittag, J., Oehr, W., Heuer, H, Hamalainen, T., Brachvogel, B., Poschl, E. and Bauer, K. 2007. Expression and thyroid hormone regulation of annexins in the anterior pituitary. J. Endocrinol. 195:385-392.

16. Moss, S.E. and Morgan, R.O. 2004. The annexins. Genome Biol. 5: 219

17. Oakes, S.R., Rogers, R.L., Naylor, M.J. and Ormandy, C.J. 2008. Prolactin regulation of mammary gland development. $J$. Mammary Gland Biol. Neoplasia. 13: 13-28.

18. Palmon, A., Ben Aroya, N., Tel-Or, S., Burstein, Y., Fridkin, M. and Koch, Y. 1994. The gene for the neuropeptide gonadotropin-releasing hormone is expressed in the mammary gland of lactating rats. Proc. Natl. Acad. Sci. U.S.A . 91: 4994-4996.

19. Ramakrishnappa, N., Rajamahendran, R., Lin, Y.M. and Leung, P.C. 2005. GnRH in non-hypothalamic reproductive tissues. Anim. Reprod. Sci. 88: 95-113.

20. Stein, T., Salomonis, N. and Gusterson, B.A. 2007. Mammary gland involution as a multi-step process. J. Mammary Gland. Biol. Neoplasia. 12: 25-35.

21. Takehara, K., Uchida, S., Marumoto, N., Asawa, T., Osugi, S., Kurusu, S., Hashimoto, I. and Kawaminami, M. 1994. Secretion of recombinant rat annexin 5 by insect cells in a baculovirus expression system. Biochem. Biophys. Res. Commun. 200: $1421-1427$.

22. van Genderen, H.O., Kenis, H., Hofstra, L., Narula, J. and Reutelingsperger, C.P. 2008. Extracellular annexin A5: functions of phosphatidylserine-binding and two-dimensional crystallization. Biochim. Biophys. Acta 1783: 953-963.

23. Watson, C.J. 2006. Post-lactational mammary gland regression: molecular basis and implications for breast cancer. Expert Rev. Mol. Med. 8: 1-15.

24. Yao, B. and Kawaminami, M. 2008. Stimulation of annexin A5 expression by gonadotropin releasing hormone $(\mathrm{GnRH})$ in the Leydig cells of rats. J. Reprod. Dev. 54: 259-264. 